\title{
Traumatic duodenal rupture in a soccer player
}

\author{
Shirzad Houshian
}

\begin{abstract}
Traumatic duodenal rupture resulting from blunt trauma during soccer is an extremely rare occurrence. A case report of this unusual condition is presented together with a review of the literature. (Br F Sports Med 2000;34:218-219)
\end{abstract}

Keywords: soccer; football; duodenal rupture; trauma

\section{Case report}

A healthy 28 year old man was admitted to the emergency department with acute midepigastric abdominal pain, having been struck in the abdomen by the knee of an opponent during a soccer game.

Physical examination on admission showed a diffusely tender abdomen with extreme rigidity, rebound tenderness, and decreased bowel sounds.

Blood pressure, pulse, and temperature were all normal. Blood analysis showed a haemoglobin concentration of $15.7 \mathrm{~g} / 100 \mathrm{ml}$, a white blood cell count of $7.4 \times 10^{9} / 1$, a $\mathrm{C}$ reactive protein concentration of $<10 \mathrm{mg} / \mathrm{l}$, and an amylase level of $66 \mathrm{mg} / 100 \mathrm{ml}$. Urine analysis was normal.

Abdominal roentgenograms and sonography were unremarkable. A contrast enhanced computed tomographic scan of his abdomen showed retroperitoneal air and distension of the small bowel (fig 1).

Acute laparotomy showed a $2 \mathrm{~cm}$ transverse anterior perforation between the descending and horizontal part of the duodenum. The perforated edges were debrided and closed in two layers. Recovery after the operation was uneventful.

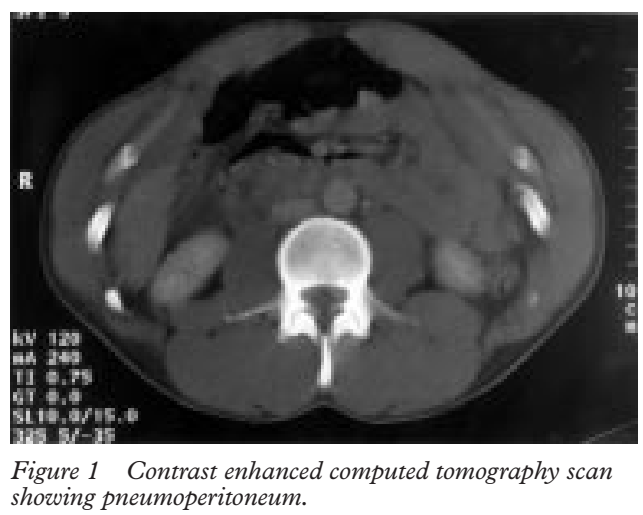

\section{Discussion}

Duodenal rupture following blunt abdominal trauma is usually related to motor vehicle accidents. ${ }^{1-3}$ Five cases of duodenal rupture following sport related blunt injury have been described in the literature. ${ }^{4-7}$ The causes of the injuries were cycling, hockey, skating, and American football.

Berqvist et al documented 136 abdominal injuries related to sports over a 30 year period in Skaraborg county, Sweden. In their study only three cases of small intestine injury were mentioned. Only three cases of jejunal rupture from sporting activities have been reported: two in American football and one in soccer. ${ }^{9}{ }^{10}$

The mechanism of intestinal rupture is variable and controversial. Most authors consider direct compression with tearing between two opposing surfaces, such as the abdominal wall and spine, to be the most likely cause of intestinal injury. ${ }^{11}$ Fixed areas of the bowel, such as the duodenum, proximal jejunum, terminal ileum, or areas with adhesions are at increased risk of injury. Because blunt abdominal trauma leaves no external sign of injury, its seriousness may be minimised or the injury completely overlooked. Abdominal pain is the most common symptom and a patient with a duodenal injury usually experiences a sharp midepigastric pain at the time of injury, followed by signs of chemical peritonitis within a few hours. The severity of signs and symptoms can vary considerably.

Early diagnosis of duodenal rupture is essential, the delay of which is associated with increased morbidity and mortality. ${ }^{13}$ The diagnosis of this injury remains problematic because the signs and symptoms of retroperitoneal viscus rupture are notoriously subtle. Free intraperitoneal air, bile, blood, and high amylase content are not usually present and depend on the severity of the injury. Contrast enhanced computed tomography is a sensitive tool for the diagnosis of pneumoperitoneum and abdominal injuries.

Although traumatic duodenal rupture is rare in the sporting population, it should be suspected in a patient with midepigastric abdominal pain, peritoneal irritation, and radiographic findings suggestive of free retroperitoneal air. A contrast enhanced computed tomography scan is the tool of choice in diagnosing duodenal rupture and is therefore recommended.

1 Snyder III WH, Weigelt JA, Watkins WL, et al. The surgical management of duodenal trauma. Arch Surg 1980;115:422-9. 
Flint LM, McCoy M, Richardson JD, et al. Duodenal injury. Ann Surg 1980;191:697-701.

Adkins RB, Keyser III JE. Recent experiences with duodenal trauma. Am Surg 1985;51:121-31.

4 Takishima T, Sugimoto K, Asari Y, et al. Characteristics of pancreatic injury in children: a comparison with such injury in adults. $\mathcal{F}$ Pediatr Surg 1996;31:896-900.

5 Cox MR, Eastman MC. Traumatic duodenal rupture and avulsion of the ampulla of vater. HPB Surg 1994;7:225-9.

6 Leshchenko AP, Saplina OI, Timoshenko LD. Rupture of the duodenum in a child. Vestn Khir Im I I Grek 1992;149: 77
7 Maemura T, Yamaghuchi Y, Yukioka T, et al. Laparoscopic drainage of an intramural duodenal hematoma. $\mathcal{f}$ Gastroenterol 1999;34:119-22.

8 Bergqvist $\mathrm{D}$, Hedelin $\mathrm{H}$, Karlsson $\mathrm{G}$, et al. Abdominal injury from sporting activities. Br F Sports Med 1982;16:76-9.

9 Baker EB. Jejunal perforation occurring in contact sports. Am 7 Sports Med 1978;6:403-4.

10 Murphy CP, Drez D. Jejunal rupture in a football player. $A m$ f Sports Med 1987;15:184-5.

11 Williams RD, Sargent FT. The mechanism of intestinal injury in trauma. $\mathcal{F}$ Trauma 1963:31;735-48.

\section{Take home message}

A case of an unusual traumatic duodenal rupture resulting from blunt trauma during a soccer game is reported. Diagnosis was by computed tomography scan. The perforated edges were debrided and closed. Recovery was uneventful.

\section{BASEM Merchandise 2000}

Ties $\quad$ Single motif

Multi motif

Blazer badge Wire -4 inches high

$£ 6+£ 1.50 \mathrm{p} \& \mathrm{p}$

Wire - 3 inches high

$£ 6+£ 1.50 \mathrm{p} \& \mathrm{p}$

$£ 5+£ 1.50 \mathrm{p} \& \mathrm{p}$

$£ 5+£ 1.50 \mathrm{p} \& \mathrm{p}$

New stock to order

Sweaters

Lambswool fine knit, V-neck or round

$£ 32+£ 3 p \& p$

neck with small motif. Machine washable.

State colour and chest size required.

Sweatshirts

With small motif.

State colour and chest size required.

Polo shirts

With small motif.

State colour and chest size required.

Some education polo shirts in cream

and grey are also available at the same price.

Send orders to John H Clegg JP BSc (Hons) DipEcon (Open) LDS RCS Eng, Hon Secretary, Birch Lea, 67 Springfield Lane, Eccleston, St Helens, Merseyside WA10 5HB, UK. (Tel and Fax: 01744 28198) 